\title{
A USABILITY RESEARCH ON TASK PREDICTION FOR EXPERIENCED USERS WITH COGTOOL
}

\author{
K. Arık
}

\begin{abstract}
Rapidly developing technology has offered different alternatives to human beings and the main target of those alternatives has been to respond to human needs. In this process, use of technology has become widespread, but it has brought some problems due to individual differences, digital competencies and generational differences. Conducting an effective process in solving those problems has also increased importance of "Human - Computer Interaction" workspace. It's not possible to evaluate users as uniform in technology human scope. Undoubtedly, in human computer interaction, user is often assumed to be "human." Cognitive modeling practices have started to be associated with many fields, from fields of psychology, engineering sciences and economics. Over $80 \%$ of articles in major theoretical journals of Cognitive Science include cognitive modeling. This research provided by 10 participants, 4 male and 6 female users who actively use Garanti BBVA Bank mobile application. Accordingly, problem of research is to prediction on whether CogTool tool makes a true accurate prediction by participants performing tasks in line with some tasks. KLM, GOMS and other cognitive models are similar to an efficient mean to exclude the application of this process was investigated. According to research results; average time of participants to perform Task 1- $5.54 \mathrm{sec}$ the lowest 4.14 sec and the highest $6.69 \mathrm{sec}$, average time for Task $2-8.67 \mathrm{sec}$ the lowest $7.59 \mathrm{sec}$ and the highest $9.45 \mathrm{sec}$ and Task 3-11.60 sec was in the lowest $10.62 \mathrm{sec}$ and the highest in $13.21 \mathrm{sec}$. Respectively, CogTool estimates for tasks performed were 6.1 secs for Task 1, 9.9 secs for Task 2 and 12.1 secs for Task 3. Accordingly, difference between real-time experience and CogTool predictions was measured as $0.56 \mathrm{sec}$ in Task $1,1.23 \mathrm{sec}$ in Task 2 and $0.50 \mathrm{sec}$ in Task 3 . In the light of those findings, it's seen CogTool tool predicts real-time results with a minor rate of error compared to average time in assigned tasks.
\end{abstract}

Keywords - CogTool, Usability, Cognitive Modeling, Experienced User

\section{INTR O D U C T I ON}

I t's not possible to evaluate users as uniform in technology human interaction. Individual differences emerge as an important factor as is known. Users needed to meet their needs more easily over time, and they have been using technology more effectively in most of their daily life. For example, while users must wait at the bank to perform their financial transactions in before, due to active use of technology, this process can now be carried out more easily in mobile application. With another example, whenever a person wants to buy any product, it can be ordered from the Internet and get it, or even return it if doesn't like it.

Kaan Arık. is with Digital Game Design Department of Art and Design Faculty Beykoz University, Istanbul, Turkey, (e-mail: kaanarik@beykoz.edu.tr).

Manuscript received Aug 16, 2019; accepted Oct 18, 2019.

Digital Object Identifier:
The term of "Human Computer Interaction" in literature aims to provide "transparent" information to users also, shape information and communication technologies according to human needs in practice and theory [1,2]

Çağıltay [3] has defined interaction of users as a structure that aims to make technology aimed at people, not technology. The basis of structure is making basic elements more usable and accessible in terms of technology's service. Turkey's acquaintance with technological devices started in 1993 when UN (United Nations) provided computer and internet access to many countries $[4,5]$.

In this period, technological tools such as computer, mobile phone and internet were used for testing in certain regions of Turkey. Turkey in the 2000s to correct Panasonic, Motorola and people began to become acquainted through phone companies such as Nokia and may use more. However, users have been unfamiliar with using technology and had difficulty in this adaptation process.

Tendency of individuals from every audience to use technology has made studies in this field important. Surely, in field of Human Computer Interaction, user is often assumed to be "human". This element also constitutes vast majority of concept that defines HCI (Human Computer Interaction). In terms of software or hardware component of some technological products, situations where you cannot select target audience or have different individual characteristics of target audience may arise. For example; Scratch application, which aims to develop software and algorithm skills for primary and secondary school students, while taking orders in banks, loading credit / money on your public transport card, or withdrawing money from ATM devices, while using kiosk devices developed to load card in a university refectory.

It can be grouped as a special audience. The change of intended group also differentiates interfaces to be designed. In addition, developing an interface to general or specific audience also reveals need to consider different areas that can be associated with HCI. At this point, research fields related with $\mathrm{HCI}$ are cognitive science, sociology, anthropology, artificial intelligence, information systems, graphic design, software and engineering. 


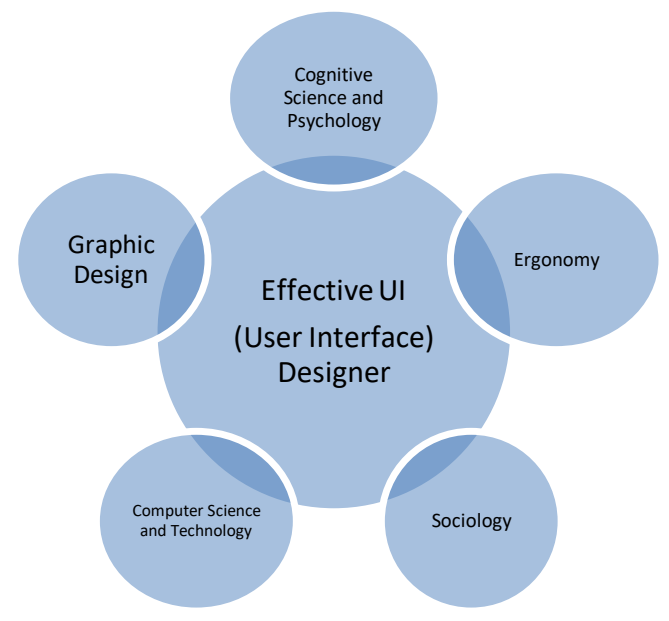

Fig.1. HCI and interactive workspaces [6]

\section{LITERATURE REVIEW}

\subsection{HCI and Cognitive Science}

Human Computer Interaction (HCI) is the science of designing an interface that is usable, understandable and responsive to requests [7]. Besides being usable and accessible, it's also a necessary structure for establishment of reliable systems.

Dreyer [8] cognitive science in psychology dictionary; defined as interdisciplinary field of science that integrates knowledge and techniques of cognitive psychology, philosophy of logic, epistemology, anthropology, psycholinguistics, neuroscience and computer science in understanding mind and mental processes. Since research problems and techniques cover many sub-disciplines, it has been difficult to define cognitive science [9].

It's known that is a field performs interdisciplinary studies with different disciplines in field of Human Computer Interaction. As seen in Figure 1, HCI is used in cognitive science and psychology problem solving skills, developing designs that are suitable for ergonomics, physical skills, anthropology and sociology interaction in terms of wider contexts, computer science and technology to establish necessary technological connection and graphic design to provide an effective interface design. [6].

Among fields mentioned above, ones that stand out in terms of social sciences can be listed as psychology and cognitive science. Cognitive science stands out as a field that deals with only cognitive processes of individuals, among structures divided into 3 groups as cognitive, affective and psychomotor. Cognitive science, in which studies began to be introduced into the literature in the 1960s, has become one of study areas that can be associated with the field of Human Computer Interaction. The evaluation of cognitive science as a sub-branch of psychology since 1980s has limited its practices in this field in a sense [10]. It was emphasized that literature in HCI and cognitive science is limited, and cognitive science is important for studies of HCI.

\subsection{HCI-Cognitive Science History and Relation}

When looking at history of humanity, important inventions have feature of being developed due to human needs. An example of that is invention of computer, development of a waterless car engine and development of different weapon technologies. However, it's worth noting that computer was originally developed to perform calculations in the military field and serves different purposes for the future. During WWII, Britain and United States appointed a team of academicians who worked in psychology to develop more effective and faster methods of training more soldiers and fighter pilots. Researchers who provided some trainings, realized that the machines individuals are trained to use can be developed using a different way [11].

Advocating that sub-disciplines of cognitive science should be brought together, like other researchers [9] emphasized there is a common area in interface design in HCI. It also suggests this content can prove a way to combine cognitive sub-disciplines in ways never seen before. At this point, main target was to investigate productive component of the unifying theme of $\mathrm{HCI}$ and content proposed for cognitive science. Practical research also removes artificiality of scientific research in the perspective of Human Computer Interaction and Cognitive Science [12].

Scientists Fredick Bartlett, Donald Broadbent, Alphanse Chapenis and Paul Fitts at the University of Cambridge conducted cognitive studies to practice in this field. Next period, Broadbent and Miller continued their studies in academic world and establish foundation of cognitive science. Studies have led to increased interest in the cognitive dimensions of the underlying causes of human behavior in development of applied sciences. In this regard, foundations of cognitive science have been started to be laid. In terms of HCI, computer innovations such as text editing, graphic processing, interfaces, and pointing devices have paved the way for gradual identification [13].

When first examples of human computer interaction and Cognitive Science studies were examined, HCI focused on more applications, cognitive science focused more on theoretical parts. In ongoing process, they brought together Human Computer Interaction and Cognitive Science disciplines and introduced a new idea for application [14]. Cognitive Science focuses more on examining cognitive process that HCI is going through. In other words, it took into account processes of perception, use and decision making. In this understanding phase, interaction between computer and user is estimated and explained. In two areas, computer scientists and experts in cognitive science collaborate jointly. Cognitive science and HCI are getting help from most of each other and are improving day by day. At the point of solution, it is not a solution to cognitive science theories to HCI, but to allow new theories arising from the applied HCI research is offered as a solution to this problem.

Advocating that sub-disciplines of cognitive science should be brought together, like other researchers [9] emphasized there is a common area in interface design in HCI. It also suggests this content can prove a way to combine cognitive sub-disciplines in ways never seen before. At this point, main target was to 
investigate productive component of the unifying theme of $\mathrm{HCI}$ and content proposed for cognitive science. Practical research also removes artificiality of scientific research in the perspective of Human Computer Interaction and Cognitive Science [12].

Scientists Fredick Bartlett, Donald Broadbent, Alphanse Chapenis and Paul Fitts at the University of Cambridge conducted cognitive studies to practice in this field. Next period, Broadbent and Miller continued their studies in academic world and establish foundation of cognitive science. Studies have led to increased interest in the cognitive dimensions of the underlying causes of human behavior in development of applied sciences. In this regard, foundations of cognitive science have been started to be laid. In terms of HCI, computer innovations such as text editing, graphic processing, interfaces, and pointing devices have paved the way for gradual identification [13].

When first examples of human computer interaction and Cognitive Science studies were examined, HCI focused on more applications, cognitive science focused more on theoretical parts. In ongoing process, they brought together Human Computer Interaction and Cognitive Science disciplines and introduced a new idea for application [14]. Cognitive Science focuses more on examining cognitive process that HCI is going through. In other words, it took into account processes of perception, use and decision making. In this understanding phase, interaction between computer and user is estimated and explained. In two areas, computer scientists and experts in cognitive science collaborate jointly. Cognitive science and HCI are getting help from most of each other and are improving day by day. At the point of solution, it is not a solution to cognitive science theories to HCI, but to allow new theories arising from the applied HCI research is offered as a solution to this problem.

\subsection{Cognitive Modeling}

Cognitive models are increasingly emerging in all areas of cognition, from perception to memory, to problem solving and decision making. Cognitive science is about understanding processes that the human brain uses to perform complex tasks such as perception, learning, remembering, thinking, guessing, inference, problem solving, decision making, planning and moving around the environment. Over $80 \%$ of articles in major theoretical journals of Cognitive Science include cognitive modeling [15].

Cognitive modeling practices have started to be associated with many fields, from psychology, engineering and economics. Thus, cognitive modeling becomes a basic tool for Cognitive Science and Social Sciences. Main purpose of a cognitive model is to scientifically explain one or more of those basic cognitive processes, or to better understand how those processes interact. In other words, cognitive modeling is one of the ways to evaluate usability of a product and those cognitive theories can solve problems by applying them. [16]. Cognitive modeling are models developed to design the interface more active and effectively.

Cognitive modeling appears as a structure that examines how individuals categorize perceptual objects in mind. For example, an individual who is an art enthusiast wants to know about the period of a painting, a scientist working in the field of social sciences, academic period of the subjects he worked on. In other words, cognitive modeling can be called the prototype of a categorization process [15]. Different models have been developed for cognitive modeling according to their usage in various fields.

For example, when we think that user should perform a task, process of understanding how an individual learns and how categorizes it in process of performing this task should be well known. This process can only be understood by scientific studies. In this respect, HCI and cognitive science need each other. Cognitive modeling is psychology-based, and also appears as a study tool in engineering for both theoretical research and practice. If the theory is well-structured, it helps to evaluate the designs of cognitive modeling interface alternatives [17]. Cognitive model is a structure used to predict how users perform before applying it through a system and even before prototyping. It's seen that cognitive modeling plays a more satisfying and supportive role in HCI than people. It can also perceptual, cognitive and motor processes to perform a task. In this process, main goal is to perform the task given with minimum effort or to act like a human and respond to as desired. Another function of cognitive science in $\mathrm{HCI}$ is to develop better interfaces for users. While achieving this goal, it can be listed as developing a better interface with the feedback from the predictions, learning time, predicting errors and predicting what should be corrected in the interface according to those predictions.

It can be said that Cognitive Science is used for 3 purposes in HCI. Those;

- Predict human behavior,

- Guiding users in an adaptable model, interaction.

- Getting efficiency from other users in group

\subsection{Cognitive Modeling - Advantages and Disadvantages}

It's not possible to evaluate individuals as a single group because some differences come to the fore. Likewise, besides the advantages of the systems used in a single group evaluation, some disadvantages may arise. In terms of advantages, cognitive modeling helps interface designers to shape many steps by instructing from early stage of design [18]. It comes to the fore with its applicability easily without spending too much time. Low costing dimension is among factors that make cognitive modeling practical. In addition, this factor also increases effectiveness in the practical use of cognitive modeling. Another advantage of cognitive modeling is to try to answer questions such as how many steps, how long it will take and how much effort it will perform in a human-computer interaction process $[14,3]$

Cognitive modeling is aimed at finding solutions to problems encountered in different interface designs in cognitive process. Besides producing different advantages, it also has a number of disadvantages. Those disadvantages; 
- Focusing on only experienced (constantly performing task) user,

- Insufficient on individual differences,

- Failure to consider user errors,

- Being able to make an estimate about the ideal process.

\subsection{Cognitive Modeling Models}

Finally, it's also worth noting that cognitive modeling should be shaped according to study to be used in terms of usage. Cognitive modeling put into perspective us a functional feature in making an prediction of task to perform between user and device in a specific time. Different cognitive models have been introduced in HCI and cognitive science. Some of those models listed in below;

- GOMS

- SOAR

- ACT-R

- EPIC

- KLM (Key Stroke Model)

-MHP (Model Human Processor)

\subsection{GOMS Model and NYNEX}

GOMS model is a feasible model in situations where users are expected to perform the task they have already mastered (performed without errors). Information collected through the GOMS model is used to predict what individual will do in unpredictable situations $[19,20]$. In a study conducted according to GOMS model, designer should inform any user whom person wants to test about the goal, method, when/how method should be used. User commands the system, system does so. It tells user what person is doing in single user transactions. In this process, GOMS is user-oriented and performs well in this type. Text graphic editors work well in functions such as page layout creation, spreadsheet creation, User Interface design, WWW, and CAD systems.

It's a comprehensive model and contains mixed items. Indicating choices outlined about objectives in cognitive processes may not always guide HCI researchers. GOMS model has remained very academic and is considered a pioneer in other models, except that it's basic model on HCI.

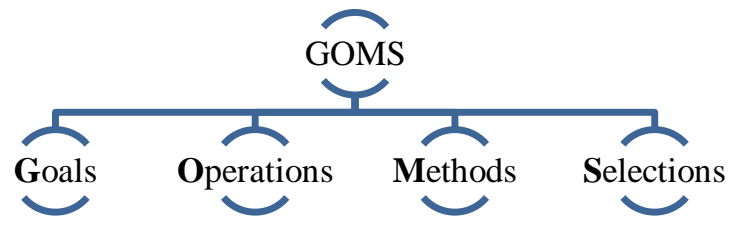

Fig.2. GOMS model and sub-dimensions

1. Goals: Those are tasks given to the user. It can also be described as actions that the design developer asks individual to take.

2. Operations: Actions that software allows the user. Person can perform a task with the mouse or can do it using shortcuts. Here transactions can be defined in this way.
3. Methods: It's way the user chooses while performing given task. Also, user can use different ways according to digital competencies.

4. Selections: If there are different methods of performing a task, user can choose between them. The factor affects here is the situation affecting the selection.

There are some various software are available to facilitate use of model-based evaluation approach. GOMS model is the best known of model-based evaluation methods. One of the best examples of GOMS model is Project Ernestine. Considering that time is equal to money in terms of call center companies, where aim is to conduct interviews, increase in 1-second call time that may occur due to one person in the interviews returns to company as an additional cost. In 1980, a telecommunications company called NYNEX shortened 1second calling time from each operator and planned to reduce company's annual expenses by $\$ 3$ million. In this respect, an application for shortening calling time will provide the company with a cost advantage. Different opinions have been put forward in this regard and the most effective among the opinions has been to reduce this time by establishing an additional station with new technological devices.

In this process, context of Project Ernestine, structures such as different keyboard layouts, screen layouts and switching procedures were compared to NYNEX company that wanted to establish a new station, and a system was proposed for the system and information about the GOMS model was provided. In the NYNEX project, analysis was performed using a cognitive model according to the GOMS model. As a result of a proposal prepared according to the GOMS model at the end of this process, he also predicted that the new devices planned to be installed will not decrease calling time and will increase those times by 0.69 seconds. If stations that are supposed to be established are not installed, company will not be able to decrease calling times and at the same time, it has been reached that this projected increase will return approximately $\$ 2$ million per year for company.

On this subject, in task analysis prepared according to model applied, company didn't establish a new station, returned from loss and implemented suggestions to be made after making an predict according to it. As mentioned above in this process, cognitive models can be used effectively and actively in every step of design process with little effort and cost.

\section{METHOD}

\subsection{Research Design and Procedure}

Participants performed given tasks via smart phones. They were selected according to convenience sampling among participants. Participants were instructed to perform tasks exactly as described to ensure the best comparison between performance and model estimates. In order to make given tasks completely correct and errorless, participants were tested as a result of some instructions. As a result of this experiment, individuals performed their basic tasks. When performing those 
tasks, it was decided to perform task again from beginning in case of any mistake, and a path was followed accordingly.

\subsection{Problem}

Problem of research is whether CogTool tool makes a real-like accurate prediction as a result of participants performing tasks in line with some tasks and whether KLM, GOMS and similar cognitive models have an effective effect in practice.

\subsection{Participants}

The research group consists of 10 people, 4 male and 6 female users, who actively use the Garanti BBVA Bank mobile application. Target audience of the application includes people who have been actively using Garanti BBVA mobile application for a while and made financial transactions using their smart phones. The participants' ages are between 26 and 46 and the average as 31.2 ages. In addition, participants were selected from those who have completed their postgraduate studies and actively work in academy.

\subsection{Research Tools}

Tests applied during research were made concrete by processing with Excel software in Windows PC. As well, CogTool which is a cognitive modeling tool in order to perform user tests and make predictions, has been the most frequently used software within framework of its study. The usage and general information of the CogTool tool is as follows.

\subsection{CogTool and Applications}

It's a free software developed by Carnegie Mellon University to measure usability of interfaces based on cognitive modeling and use ACT-R architectures. CogTool is a general-purpose user interface prototyping tool. It automatically evaluates designs with a predictable human performance model. CogTool can be used to base existing interface, compare competitors' interfaces, and predict how good your new designs will be. Psychomotor and cognitive processes help us make an average estimate for experienced users and provide an example of a prediction to those who have developed design interface so that user can take action. It's used to carry out procedures on how long was spent on a required task or what an experienced user is on a task.

Advantages of CogTool;

- Provides feedback in order to develop reusable designs,

- Measure the performance for different designs,

- Gives a chance to make an evaluation against competitors,

- It can be used very beginning to the end of the product development process.

In addition to theory, it enables implementation of cognitive models in practice. Assuming that you are a company owner and need to develop an interface, an experienced user will provide an predict of how long it takes to perform a task on a desired platform, and as a result of this estimate, you might have information about how useful the interface you want to develop. In this way, the CogTool tool has demonstrated its effectiveness in practice and has been actively used to provide users with realistic results. Also, CogTool is a software provides fast and practical results, guessing quantitative data, based on acting as if there is a user without an existing user.

\subsection{Tasks}

\begin{tabular}{|c|l|c|c|}
\hline No & Instruction & Difficulty & Steps \\
\hline 1 & Finding the IBAN number of personal account & Easy & 2 \\
\hline 2 & Finding current debt of any registered bill & Normal & 6 \\
\hline 3 & $\begin{array}{l}\text { Finding current acc count activity of the personal card for last 1 } \\
\text { month }\end{array}$ & Hard & 7 \\
\hline
\end{tabular}

Fig.3. Task, difficulty and steps

Tasks and steps that participants are asked to perform within the scope of our study. While determining tasks, most used features and critical operations that can be performed by using application are taken into consideration in Garanti BBVA mobile application. It has been assigned some tasks related to mobile application of Garanti BBVA. In this process, it's expected to perform tasks with the users logged on. Those tasks and difficulty levels given to participants are listed below and quantitative data of research are detailed below in the Findings section.

\section{FINDINGS}

\begin{tabular}{|l|c|c|c|c|c|}
\cline { 3 - 5 } \multicolumn{1}{c|}{} & \multirow{2}{*}{$\begin{array}{c}\text { Mean Time } \\
(\mathbf{s e c})\end{array}$} & $\begin{array}{c}\text { Minimum } \\
\text { (sec) }\end{array}$ & $\begin{array}{c}\text { Maximum } \\
(\mathbf{s e c})\end{array}$ & $\begin{array}{c}\text { Cog Pool } \\
\text { Prediction } \\
(\mathbf{s e c})\end{array}$ & $\begin{array}{c}\text { Difference } \\
(\mathbf{s e c})\end{array}$ \\
\hline Task 1 & 5,54 & 4,14 & 6,69 & 6,1 & 0,56 \\
\hline Task 2 & 8,67 & 7,59 & 9,45 & 9,9 & 1,23 \\
\hline Ta sk 3 & 11,60 & 10,62 & 13,21 & 12,1 & 0,50 \\
\hline
\end{tabular}

Fig.4. Participants' time to perform assigned tasks and CogTool predictions.

As seen in Table 1, duration of participants assigned tasks and average time to perform Task 1 is $5.54 \mathrm{sec}$ - the lowest $4.14 \mathrm{sec}$ and the highest is $6.69 \mathrm{sec}$, Task 2 is $8.67 \mathrm{sec}$ - the lowest 7.5 sec and the highest time was $9.45 \mathrm{sec}$ and average time was $11.60 \mathrm{sec}$, the lowest was $10.62 \mathrm{sec}$ and the highest was 13.21 sec. Respectively, CogTool prediction for tasks performed were $6.1 \mathrm{sec}$ for Task 1, $9.9 \mathrm{sec}$ for Task 2 and $12.1 \mathrm{sec}$ for Task 3. Accordingly, between real-time experience and CogTool estimates, 0.56 seconds in Task 1, 1.23 seconds in Task 2 and 0.50 in Task 3 were measured. In the light of those data, it's seen CogTool tool predicts life-like results with a small rate of error compared to the average time in assigned tasks. List of tasks assigned to participants is given in Table 2, Table 3 and Table 4 with details.

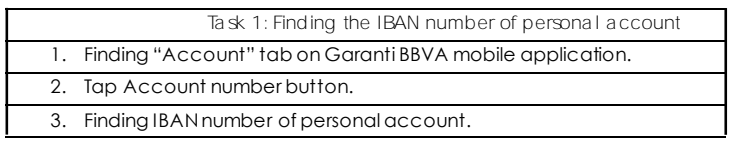


Fig.5. Participants' time to perform assigned Task 1 and steps.

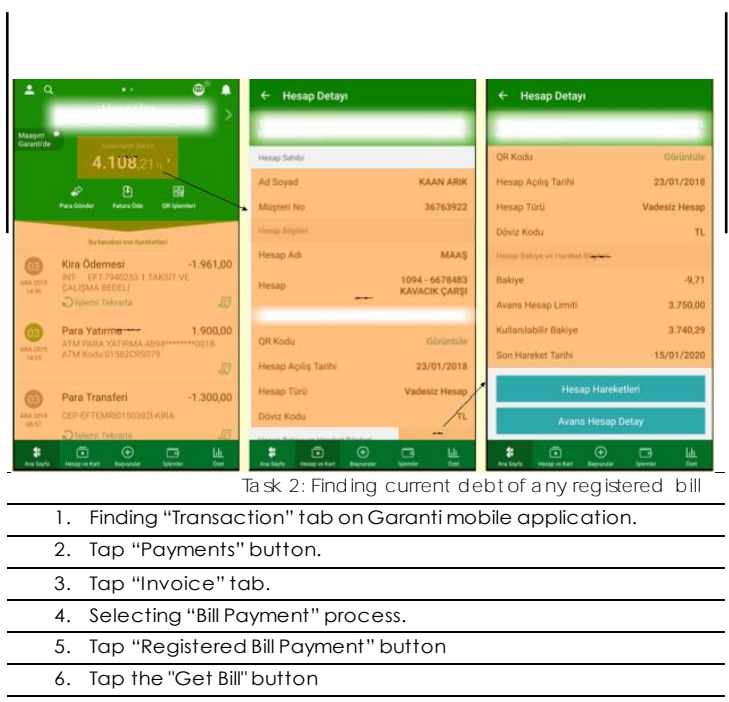

Fig .6. Participants' time to perform assigned Task 2 and steps.

Ta sk 3: Find ing current a ccount a ctivity of the personal ca rd for last 1 month

\begin{tabular}{|l|l|}
\hline 1. & Tap "Account and Card" section. \\
\hline 2. & Touching "Accounts" button. \\
\hline 3. & Tap on the deposit account. \\
\hline 4. & Moving page down and touching "Account Transactions" button. \\
\hline 5. & Touching "Last 7 Days" button on the Account Transactions page. \\
\hline 6. & Selecting "Last 1 Month" from the pop-up menü. \\
\hline 7. & A cursory glance on detailed account. \\
\hline
\end{tabular}

Fig.7. Participants' time to perform assigned Task 3 and steps.

As seen in Figure 1, users were asked to access and review their account information under Task 1 . A button was added to the Accounts section via CogTool, and a review plugin was included in other sections. Steps of cognitive processes were shown in Figure 2.

Fig.8. Participants' follow steps while performing Task 1

\begin{tabular}{|l|l|l}
\hline Frame & Action & Widget/Device \\
1 & Look At & HEAP HAREKETLERi (Widget 1) \\
1 & Think for 1.200 s & \\
\hline 1 & Move and Tap & BAKIYE_BUTON (Widget 2) \\
\hline 2 & Look At & HESAP DETAYI (Widget 1) \\
\hline 2 & Move and Tap & BUTON2 (Widget 2) \\
3 & Look At & HESAP-DETAYI2 (Widget 2) \\
3 & Think for 1.200 s & \\
\hline & &
\end{tabular}

Fig.9. Steps of prediction for Task 1 with CogTool

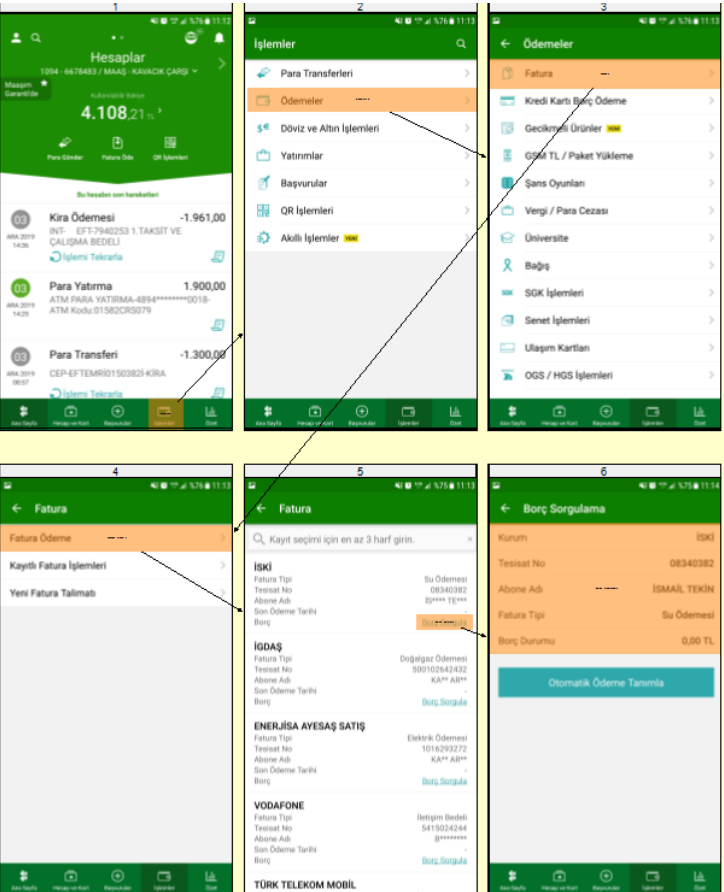

Fig.10. Participants' follow steps while performing Task 2

As seen in Figure 3, users were asked to find the invoice debt registered under Task 2. On the existing screen, initially, "Transactions" $\rightarrow$ "Payments" $\rightarrow$ "Invoice" $\rightarrow$ "Invoice Payment" and "Inquiry" button of the desired invoice was examined to examine the incoming query. Steps of the cognitive processes were shown in Figure 4.

\begin{tabular}{|l|l|l|}
\hline Frame & Action & Widget/Device \\
\hline 1 & Think for 1.200 s & \\
1 & Move and Tap & işLEMLER (Widget 1) \\
\hline 2 & Think for 1.200 s & \\
\hline 2 & Move and Tap & ÖDEMELER (Widget 1) \\
\hline 3 & Think for 1.200 s & \\
\hline 3 & Move and Tap & FATURA (Widget 1) \\
\hline 4 & Think for 1.200 s & \\
\hline 4 & Move and Tap & FATURA ÖDEME (Widget 1) \\
\hline 5 & Think for 1.200 s & \\
\hline 5 & Move and Tap & BORÇ SOGULA (Widget 1) \\
6 & Look At & BORÇ ORGULAMA (Widget 1) \\
6 & Think for 1.200 s & \\
\hline- & & \\
\hline
\end{tabular}

Fig.11. Steps of prediction for Task 2 with CogTool 


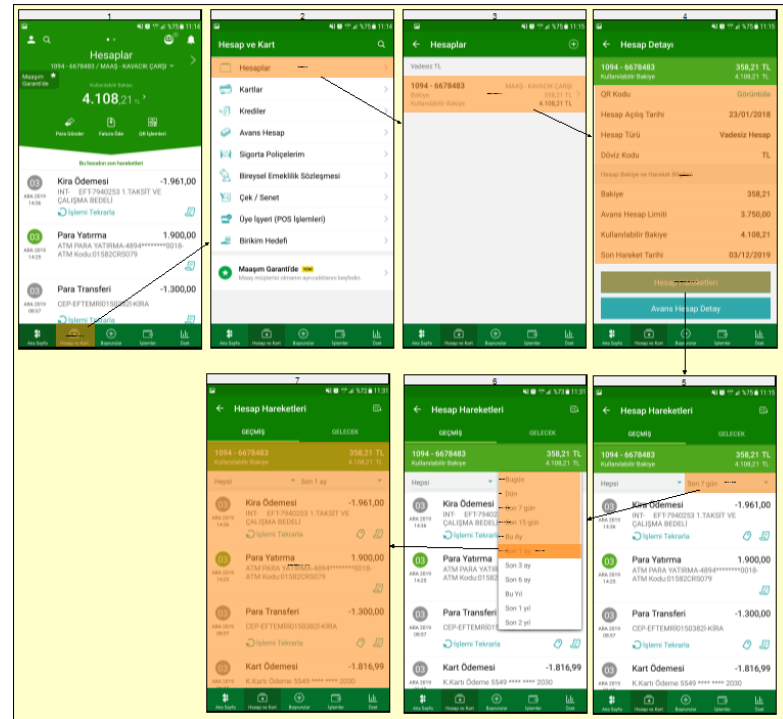

Fig.12. Participants' follow steps while performing Task 3

As seen in Figure 5, users were asked to check and examine the last 1-month account activity within Task 3 . In the existing screen, initially, "Accounts" $\rightarrow$ "Accounts" tab $\rightarrow$ "Entering the Current Account" $\rightarrow$ "Opening Account Details" and the "Last 1 Month" button of the desired account, the process of examining the account details was performed. Steps of cognitive processes were shown in Figure 6.

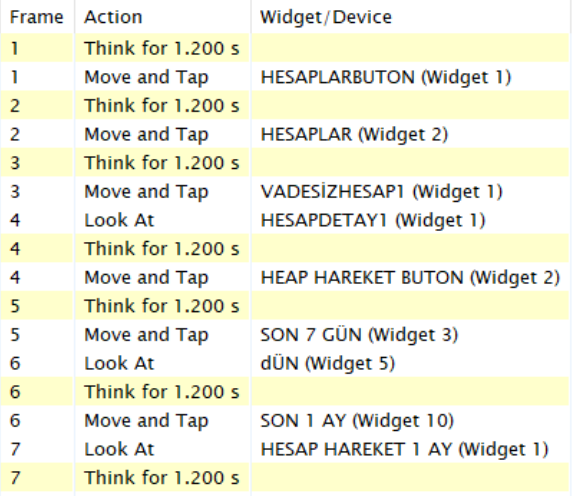

Fig.13. Steps of prediction for Task 3 with CogTool

As seen in Figure 7, 8, and 9, it's seen that estimated duration of expenditure is visualized for the dimensions created by taking into account made by CogTool. In this section, vision, eye movement realization and preparation, cognitive process and hand movement dimensions are presented in prediction. Amount of time allocated to which size is given below.

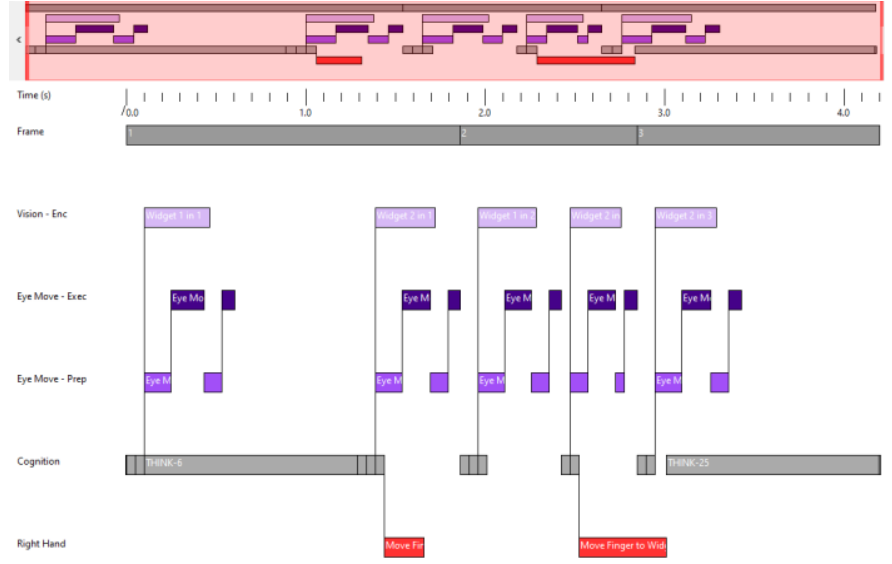

Fig.14. Visualization of CogTool's prediction for Task 1
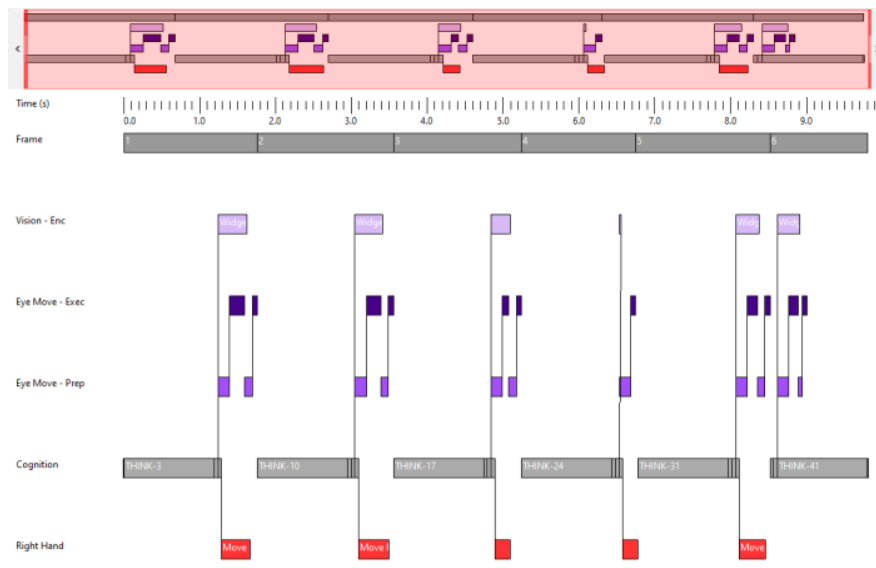

Fig.15. Visualization of CogTool's prediction for Task 2

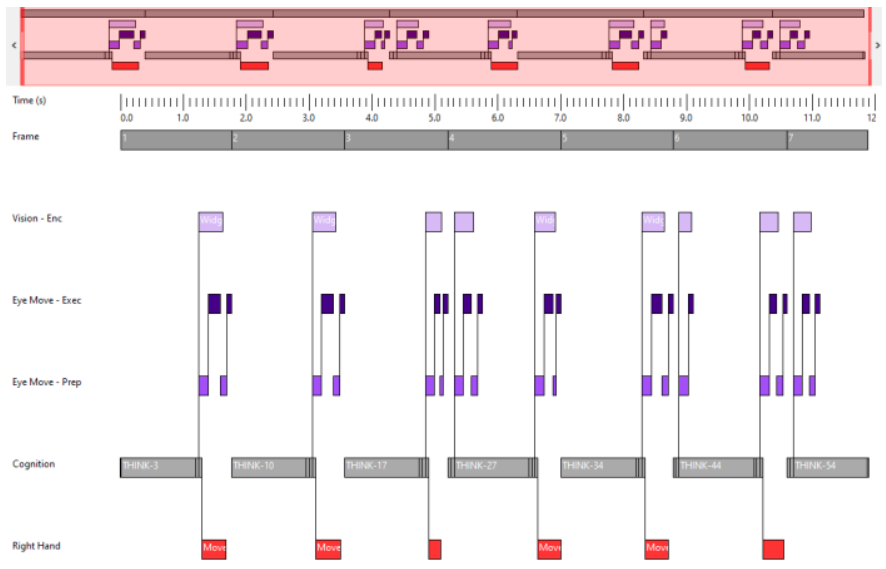

Fig.16. Visualization of CogTool's prediction for Task 3 


\section{CONCLUSIONS}

CogTool-like tools run a system prediction based on cognitive modeling theories. Aim is to make an inference about how long experienced users can perform a task by conducting a prediction. Academicians concluded experienced users in the field of CogTool and cognitive modeling are a tool that makes close predictions about testing the interface design for usability. $[17,21,22,23,24,25,26]$. In CogTool predictions, error rate is limited as $20 \%$. Very small rate of error gained more importance as CogTool made lifelike predictions in terms of developing the interface. Likewise, as mentioned above, NYNEX project has been essential for company to take a precaution without applying certain activities, which can be applied to individuals and give efficient results.

On the other hand, while studies conducted with the CogTool tool are available, it's argued that number of scientists working in the same field are not reliable and that the predictions in use for CogTool-like usability are not reliable and do not yield predictive results in use.

In the study of CogTool tool with experienced users by giving certain tasks about certain models, they also concluded that the difference between interface alternatives regarding human performance is not predicted sufficiently and does not give results close to normal and it is not a reliable tool in decision making on KLM, GOMS and CogTool based interface design $[27,28,29]$.

In last studies performed in $\mathrm{HCI}, \mathrm{Cog}$ Tool has been argued that it makes a close prediction in real-time tasks, and in other studies it has moved away from real-time tasks. However, the number of these articles was found to be low. It has generally been shown to produce realistic results.

\section{REFERENCES}

[1] Shneiderman, B. (1980). Software psychology: human factors in computer and information systems. Cambridge, Mass: Winthrop Publishers.

[2] Weinberg, G. M. (1998). The psychology of computer programming (Silver anniversary ed). New York: Dorset House Pub.

[3] Çağıltay, K. (2018). Teoriden Pratiğe İnsan - Bilgisayar Etkileşimi ve Kullanılabilirlik Mühendisliği (2. bs). İstanbul: Seçkin Yayıncılık.

[4] Acartürk, C., \& Çăğltay, K. (2006). İnsan bilgisayar etkileşimi ve ODTÜ'de yürütülen çalışmalar. Akademik Bilişisim, 6, 9-11.

[5] Çağıltay, K. (1995). Herkes için internet. Ankara: ODTÜ.

[6] Dix, A., Finlay, J., Abowd, G. D., \& Beale, R. (2004). Human-computer interaction (3rd ed). Harlow, England; New York: Pearson/Prentice-Hall.

[7] Dillon, R. F. (1983). Human factors in user-computer interaction: An introduction. Behavior Research Methods \& Instrumentation, 15(2), 195199. https://doi.org/10.3758/BF03203548

[8] Dreyer, J. (1981). The Penguin dictionary of psychology. Harmondsworth: Penguin Books.

[9] Boring, R. L. (2002). Human-Computer Interaction as Cognitive Science. Proceedings of the Human Factors and Ergonomics Society Annual Meeting, 46(21), 1767-1771. https://doi.org/10.1177/154193120204602103

[10] Ertürk, E. M. (2017). Bilimsel psikolojinin tarihsel süreci üzerine. Trakya Üniversitesi Edebiyat Fakültesi Dergisi, 7(14), 161-180.

[11] Meister, D. (1999). The history of human factors and ergonomics. Mahwah, N.J: Lawrence Erlbaum Associates.

[12] Hollan, J., Hutchins, E., \& Kirsh, D. (2000). Distributed cognition: toward a new foundation for human-computer interaction research. ACM Transactions on Computer-Human Interaction, 7(2), 174-196. https://doi.org/10.1145/353485.353487

[13] Myers, B. A. (1998). A brief history of human-computer interaction technology. $\quad$ interactions, $5(2)$, $44-54$. https://doi.org/10.1145/274430.274436
[14] Card, S. K., Moran, T. P., \& Newell, A. (1983). The psychology of human-computer interaction (Reprinted). Boca Raton, Fla. London New York: CRC Press.

[15] Busemeyer, J. R., \& Diederich, A. (2010). Cognitive modeling. Los Angeles: Sage Publishing.

[16] Olson, J. R., \& Olson, G. M. (1990). The Growth of Cognitive Modeling in Human-Computer Interaction Since GOMS. Human-computer interaction, 5, 221-265.

[17] Gray, W. D., John, B. E., \& Atwood, M. E. (1993). Project Ernestine: Validating a GOMS analysis for predicting and explaining real-world task performance. Human-computer interaction, 8(3), 237-309.

[18] Cox, A. L., \& Peebles, D. (2008). Cognitive modelling in HCI research. Cambridge University Press.

[19] John, B. E. (1995). Why GOMS? interactions, 2(4), 80-89 https://doi.org/10.1145/225362.225374

[20] Peebles, D., \& Banks, A. (2010). Modelling dynamic decision making with the ACT-R cognitive architecture. Journal of Artificial General Intelligence, 2(2), 52-68.

[21] Held, T., \& Schrepp, M. (2011). Effective cognitive modeling for business software - Where and how can cognitive models support usability professionals in their everyday work? Proceedings of Usability Professionals Association International Conference Book, 1-12.

[22] John, B. E. (2005). Cognitive Human Performance Modeling by Demonstration. Proceedings of the Human Factors and Ergonomics Society Annual Meeting, 49, 1153-1156. SAGE Publications Sage CA: Los Angeles, CA.

[23] John, B. E., \& Suzuki, S. (2009). Toward cognitive modeling for predicting usability. International Conference on Human-Computer Interaction, 267-276. Springer.

[24] Luo, L., \& John, B. E. (2005). Predicting task execution time on handheld devices using the keystroke-level model. CHI'05 extended abstracts on Human factors in computing systems, 1605-1608. ACM.

[25] Ocak, N., \& Cagiltay, K. (2017). Comparison of cognitive modeling and user performance analysis for touch screen mobile interface design. International Journal of Human-Computer Interaction, 33(8), 633-641.

[26] Swearngin, A., Cohen, M. B., John, B. E., \& Bellamy, R. K. (2013). Human performance regression testing. Proceedings of the 2013 International Conference on Software Engineering, 152-161. IEEE Press.

[27] Jorritsma, W., Haga, P.-J., Cnossen, F., Dierckx, R. A., Oudkerk, M., \& van Ooijen, P. M. (2015). Predicting human performance differences on multiple interface alternatives: KLM, GOMS and CogTool are unreliable. Procedia Manufacturing, 3, 3725-3731.

[28] Lee, J., \& Billman, D. (2011). Modeling performance differences across systems, tasks, and strategies. Proceedings of the Annual Meeting of the Cognitive Science Society, 33.

[29] Salvucci, D. D., \& Lee, F. J. (2003). Simple cognitive modeling in a complex cognitive architecture. Proceedings of the SIGCHI conference on Human factors in computing systems, 265-272. ACM.

\section{B I O G R A P H Y}

Kaan Arık obtained his BSc degree in Computer and Instructional Technologies Education from Sakarya University (SAU) in 2015. He received the BSc., and MSc. diploma in Computer and Instructional Technologies Educationfrom the Sakarya University in 2018 and still student of $\mathrm{PhD}$ in İstanbul University, Informatics Department. Also, he currently works at the Department of Digital Game Design, Beykoz University. His research areas related with Game Design, Machine Learning, Computer Human Interaction and Deep Learning. He also aims to work in interdisciplinary fields of study. 